It took 50 years for midwives to administer nitrous oxide to patients in labour. I look forward to the day when they are trained to provide epidural analgesia.

A B W TAYLOR

Bowthorpe Maternity Hospital,

Bowthorpe Mate
Wisbech, Cambs

SIR,-I have read the article by Mr A B W Taylor and others (6 August, p 370) with interest. However, I firmly believe that at the present time an obstetric epidural service should be provided by anaesthetists and should be available only when there is a resident anaesthetist on call in the hospital.

The reason for this uncompromising attitude is that the greatest among the risks inherent in the procedure is the possibility of local anaesthetic being introduced into the cerebrospinal fluid. The resultant "total spinal anaesthesia" is a situation requiring resuscitation skills of the highest order, and when these are present a fatal outcome can be prevented. In this situation I think that anaesthetists, by virtue of their training and constant practice in this field, are much more likely to be successful than obstetricians. It is one thing for the latter to be taught to pass an endotracheal tube in the anaesthetic room under ideal conditions but a totally different one for them to cope with this and other aspects of management in the acute state of chaos that would be precipitated by a "total spinal" occurring in a labour ward.

I was relieved to see that Mr Taylor's team did take steps to minimise the possibility of high spinal anaesthesia. Unfortunately there is no way of ensuring it will not happen, nor is it always a complication apparent with the first dose of local anaesthetic. Obstetric epidurals have been a momentous step forward, but until we have accurate data on the incidence of complications and a realistic assessment of the procedures I do not think it is justified to relax the standards that have so far been applied to its use in Britain.

J M ANDERTON

Royal Infirmary,

Manchester

\section{Metronidazole neuropathy}

SIR,-Further to the account of recovery in metronidazole neuropathy by Professor W G Bradley and others (3 September, p 610) we wish to report a case in which complete subjective recovery has not apparently resulted two years after discontinuing the drug.

The patient is a 20-year-old girl with extensive Crohn's disease and episodes of bacteraemia and abscess formation. Prior to surgery she was treated with oral metronidazole $800 \mathrm{mg}$ twice daily for seven weeks before developing numbness of the hands and feet. Examination then demonstrated diminished ankle jerks and reduced sensibility to pinprick and cotton wool below mid-calf. There was also apparent left calf muscle wasting, but weakness was not present. Fasting blood sugar, folate, and vitamin $B_{12}$ levels were normal; other drugs currently taken were prednisone, folic acid, and ferrous sulphate.

The metronidazole was discontinued and the hand numbness resolved over four weeks. Fourteen weeks after withdrawal of the drug the tendon reflexes were brisk and sensory testing revealed distal hyperaesthesia in the legs, more marked on the left. However, two years later she continues to be distressed by numbness in the feet, although objective signs are questionable. The patient has not consented to nerve conduction studies.
In all previously reported cases, ${ }^{1-4}$ as in that reported by Professor Bradley and his colleagues, full symptomatic recovery was generally apparent within four months of metronid azole withdrawal. This case is exceptional for the duration of symptoms in the lower limbs. The total amount of metronidazole in reported cases of neuropathy has ranged between 30 and $314 \mathrm{~g}$. In this instance it was $78 \mathrm{~g}$, implying that duration and severity of symptoms in metronidazole neuropathy may not be strictly dose-related.

I J KARLSSON Royal Victoria Infirmary
Newcastle upon Tyne

I Ingham, H R, et al, fournal of Antimicrobial Chemotherapy, 1975, 1, 355 Ursing, B, and Kamme, C, Lancet, 1975, 1, 775. 3 Ramsay, I D, British Medical fournal, 1968, 4, 706. Neurosurgery and Psychiatry, 1976, 39, 403 .
Neurology

SIR,-Dr W G Bradley and his colleagues (3 September, p 610) state that metronidazole neuropathy is mild and recovery appears to be complete. We strongly disagree. Although the patients described by Ursing and Kamme indeed fared well, those described by Ramsay and by Coxon and Pallis ${ }^{3}$ developed a severe neuropathy which certainly did not regress completely on stopping the drug. We have a further patient who developed a severe sensory neuropathy with intolerable dysaesthesiae four months after starting metronidazole for Crohn's disease. Seven months after stopping the drug there has been no improvement, either clinically or in nerve conduction studies.

In our view patients starting long-term therapy with metronidazole should be specifically warned about this complication and should be told to stop the drug and report immediately if any neurological symptoms occur.

S HISHON John Pilling

Norfolk and Norwich Hospital,

Norwich 1 Ursing, B, and Kamme, C, Lancet, 1975, 1, 775.
2 Ramsay, I D, British Medical fournal, 1968, 4, 706. Coxon, A, and Pallis, C A, fournal of Neurology,
Neurosurgery and Psychiatry, 1976, 39, 403 .

\section{Shortage of anaesthetists}

SIR,-Mr A W Fowler (27 August, p 576) makes a plea for the increasing use of loca anaesthesia for surgical procedures and advocates a combination of diazepam and Cyclimorph. May I offer him an alternative technique which is enjoying popularity in denta circles and which he might find of value?

Dentists are, for obvious reasons, very keen to avoid nauseating drugs. The combination of cyclizine and morphine in Cyclimorph seems designed to produce narcosis withou nausea but, as $\mathrm{Mr}$ Fowler admits, this may only postpone the nausea so that it embarrasses the nursing staff rather than the surgeon. An alternative which has been found virtually non-nauseating is to use pentazocine with the diazepam. A standard dosage of $30 \mathrm{mg}$ pentazocine intravenously will produce analgesia comparable with that produced by $10 \mathrm{mg}$ morphine but without the nausea. This is then supplemented by diazepam given intravenously at the rate of $2.5 \mathrm{mg} / 30 \mathrm{~s}$ until sedation is evident. Both drugs take some minutes to reach their full effect and so the administration of diazepam is stopped short of the desired point in the knowledge that sedation will deepen. The stage of ptosis where the upper eyelid droops to bisect the pupil has been found to be a reliable sign of adequate sedation.

Using this method it is possible to perform a single dental extraction without further anaesthesia, and together with effective local anaesthesia the most complicated surgical extractions may be performed without disturbing the patient and without leaving any memory of the procedures. This would seem to equate with $\mathrm{Mr}$ Fowler's reduction of fractures and orthopaedic operations.

It is also surprising how little diazepam is actually needed to eliminate distress and produce anterograde amnesia, and in dental operations I have never found any need for more than $20 \mathrm{mg}$ of diazepam in combination with pentazocine. Readers will no doubt assess for themselves the degree of fear which is inspired by dental procedures as distinct from those on any other part of the body.

Finally, although long-term medication with benzodiazepines may well lessen the effect of diazepam, in practice this does not so far seem to be much of a problem. Dosage may be increased, but since one is working with an "approach dose" technique the result is still effective. It would be interesting to know whether $\mathrm{Mr}$ Fowler has come across any grossly increased dosage-or, indeed, any failures of sedation-which might be attributed to benzodiazepine habituation.

P SYKES

Ampthill, Beds

\section{Strawberry pickers' foot drop}

SIR,-In reply to recent letters concerning strawberry pickers' foot drop I write to inform you that this is a relatively common disorder in the Fenland area during the strawberry season.

I had been completely unaware of this condition until I arrived here and was most alarmed at the first case that I saw but was quickly reassured by one of my senior partners. Between us in this group practice of six we have seen five cases of this disorder this year and we feel that the majority of them tend to be in casual labourers who are less aware of the consequences of continued crouching. It is a condition very rarely seen in the fenman.

K E WARREN

Wisbech, Cambs

**This correspondence is now closed.-ED,

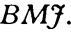

\section{Inhumanity to man}

SIR, - The title of your leading article (3 September, p 591) makes your position clear, and many should agree with you that the increasing failure of psychiatric hospitals to admit patients who have committed offences is inhumane. Yet as the problem becomes increasingly acute, swelling the prison population (at a cost of over $£ 4000$ a year per inmate), there seems to be no effort to solve it or at least ease it. The regional secure units, in the planning stage, will cope with only a minute proportion of patients requiring hospital care, and none is yet established, but by 